\title{
Inventory Control Policies for Substitutable Deteriorating Items Under Quadratic Demand
}

\author{
Nita H. Shah \\ Department of Mathematics \\ Gujarat University, Ahmedabad - 380009, Gujarat, India \\ Email: nitashah@gmail.com (Corresponding Author)
}

Urmila Chaudhari

Government Polytechnic Dahod, Dahod - 389151, Gujarat, India

Email: chaudhariurmi04@gmail.com

\author{
Mrudul Y. Jani \\ Department of Applied Sciences, Faculty of Engineering \& Technology \\ Parul University, Vadodara - 39170, Gujarat, India \\ Email: janimrudu107@gmail.com
}

\begin{abstract}
In today's busy life, no one has sufficient time to buy or bargain any type of products. It is common in such cases that customers, who are looking for purchasing a certain product, will be willing to substitute with a comparable product when facing a stock-out, rather than visiting a different store to bargain the original product. In this article, we study an inventory control problem in which demand is fulfilled by using two similar substitutable items. Retailer fulfilled demand of one product by other substitutable product when stock-out of the one of them. We consider inventory levels of both of the items and time dependent demand. The orders for both products are placed at the same time. Our objective is to maximize joint profit for two substitutable deteriorating items with respect to cycle time and a time at which one product is stock-out.The numerical analysis is carried out based on the analytical results. The critical inventory parameters are computed for the decision maker.
\end{abstract}

Keywords: inventory control, constant deterioration, quadratic demand, substitutable products

\section{INTRODUCTION}

In this throat-cut business world, there are many substitutable products in the market for competition. As we know that at any trades or superstore the occurrence of provisional stock-outs is a very common sensation in the classifications of often purchased items and it is also very common to see at any trades or superstore, consumers who eager to buy certain products will be willing to buy the substitute products, if they confronted the situation of the stock-outs. A survey report of Anupindi et al. (1998) also perceived the same sensation, in which he found that 82 $88 \%$ of consumer would be willing to buy the substitute items if the desired items are out of stock. The substitutable items in which adequate deterioration can take place during the normal storage period of the units and subsequently this loss must be taken into account when analysing the inventory system of substitutable items, i.e. the effect of deterioration plays a vital role in the choice of ordering amount of substitutable deteriorating items. When substitution will take place an additional cost is incurred, known as substitution cost. Such substitution costs may arise due to a diversity of causes: the cost of the reworking required on an item to make it substitutable for the other, loss of a customer's goodwill due to substitution, etc. The demand of smart phone remains in the market. When next generation smart phone is launched, its demand increasing linearly due to its features for certain time and then gets maturity in demand and later on demand starts decreasing exponentially due to new arrivals. The model proposed here can also be applied to automobiles industry, computer industry etc. In day to day life, one can visualize for the small scale retailers of milk products. Very few research is focussed on this concept. So, we consider in this paper quadratic demand. There are some citations in which they have taken quadratic demand.

In a general practice, demand rarely remains constant for infinite horizon. Shah et al. (2011) estimated a coordinated decision with two level credit limit for quadratic demand, which can be seen in seasonal items, fashion goods etc. It is observed in the market that with the presentation of contemporary generation product, market demand of the previous product decreases enormously. Shah et al. (2013) determine an optimal shipments, ordering, and imbursement policies for integrated vendor-buyer inventory system with net credit price-sensitive trapezoidal demand. Shah et al. (2015) evaluated an optimal down-stream credit period and cycle time for deteriorating inventory in a supply chain. Later, Shah et al. (2016) studied the model on the impact of future price increase on ordering policies for perishable items under quadratic demand. Recently, Shah et al. (2017) determined a deteriorate inventory model with expiration date of items under two level trade credit and preservation technology investment for time and price sensitive demand with DCF approach. 
Deterioration of substances likes, explosive liquors, fruitless, taters, brews, remedy, blood etc. in form of conventional deterioration or damage, on-going corporeal decay in course of time, or desuetude is a natural existence and it has extensive effect on the player's inventory strategies. Ghare and Scharender (1963) and Raafat (1991) studied model for deteriorating item. Aggarwal and Jaggi (1995) developed inventory policies for deteriorating items under trade credit. Goyal and Giri (2001) studied inventory model for deteriorating item on recent drifts. Later, Yang (2005) estimated a model of comparison among numerous partial backlogging inventory models for deteriorating item. Pattnaik (2012) established a note on non-linear profitmaximization entropic order quantity (EnOQ) model for deteriorating items with stock dependent demand rate. Dye and Hsieh (2012) given a concept of preservation technology for deteriorating items. Avinadav et al. (2013) develop an inventory model for a perishable item with demand function sensitive to price and time. Dye (2013)estimated the effect of preservation technology investment on a non-instantaneous perishable inventory model. Taleizadeh and Nematollahi (2014) projected an inventory control problem for perishable items with financial deliberations and back-ordering. Fauza et al. (2015) analyzed a vendor-buyer inventory model for food products based on shelf-life pricing. Rabbani et al. (2015) instituted the model for supply chain of noninstantaneous stock dependent deterioration. Shah and Chaudhari (2015) studied an optimal policies time and credit dependent demand for three players with fixed life time and two-level trade credit. Furthermore, Zhang, et al. (2015) analyzed an integrated model for deteriorating item with revenue sharing and cooperative investment contract. Recently, Shah and Jani (2016) determined an inventory model for perishable item of fixed-life time with quadratic demand and up and down stream trade credit.

The firstly introduced inventory model of substitutable item by McGillivray and Silver (1978) by considering that all of the substitutable products have the same unit variable cost and shortage forfeit. Pasternack and Drezner (1991) formulated numerically that if the products are not substitutable then the related optimal order quantities can be enough. Furthermore, Drezner et al. (1995) established an EOQ model with comparison between two substitution and non-substitutable products. Gurnani and Drezner (2000) extended the model of Drezner et al. (1995) for multiple items. Mishra and Raghunathan (2004) provided new clarification for why buyers might be interested in vendormanaged inventory and showed that vendor-managed inventory exaggerates the competition between two makers of competing brands. In continuation of this, Schulz and Telha (2011) developed a model for the JRP with constant demands may have no polynomial-time algorithm. Krommyda et al. (2015), Salameh et al. (2014), Rasouli and Kamalabadi (2014), and Gerchak and Grosfeld (1999) advanced inventory model for two substitutable item with deterministic demand, fixed ordering cost and constant holding cost but no one deliberated the effect of deterioration in inventory decision of substitutable items. Zhao et al. (2014) determined the pricing policy for two substitutable products with price-dependent probabilistic demand with fixed ordering cost and constant holding cost. See Table 1 for a comparison of existing models and our model based on the service level constraint.
Table 1: Contribution of different authors

\begin{tabular}{ccc}
\hline Deterioration & $\begin{array}{c}\text { Time } \\
\text { dependent } \\
\text { demand }\end{array}$ & $\begin{array}{c}\text { Substitutable } \\
\text { items }\end{array}$ \\
\hline
\end{tabular}

\begin{tabular}{r|cc} 
(1995) & $\sqrt{ }$ & \\
Aggarwal and Jaggi & & $\sqrt{ }$ \\
Anupindi et al. (1998) & & $\sqrt{ }$ \\
Avinadav et al. (2013) & $\sqrt{ }$ & \\
Drezner et al. (1995) & & $\sqrt{ }$ \\
Dye and Hsieh (2012) & $\sqrt{ }$ & \\
Dye (2013) & $\sqrt{ }$ & \\
Gerchak and & & \\
Grosfeld-Nir (1999) & & $\sqrt{ }$ \\
Ghare and & $\sqrt{ }$ & $\sqrt{ }$ \\
Scharender (1963) & & \\
Goyal and Giri (2001) & $\sqrt{ }$ & \\
Gurnani and Drezner & & $\sqrt{(2000)}$ \\
Pasternack and & & \\
Drezner (1991) & & \\
Pattnaik (2012) & $\sqrt{ }$ \\
Rabbani et al. (2015) & $\sqrt{ }$ & \\
Rasouli and & & $\sqrt{ }$ \\
NakhaiKamalabadi & & \\
(2014) & & $\sqrt{ }$ \\
Taleizadeh and & $\sqrt{ }$ & \\
Nematollahi (2014) & & $\sqrt{ }$ \\
Yang (2005) & $\sqrt{ }$ \\
Zhao et al. (2014) & & $\sqrt{ }$ \\
This Study & $\sqrt{ }$ &
\end{tabular}

In this article, we consider stock and time dependent quadratic demand with constant deterioration of two substitutable items. In addition, we study an inventory control problem in which demand is fulfilled by using two similar substitutable items. Retailer fulfilled demand of one product by other substitutable product when stock-out of the one of them. We consider inventory levels of both of the items and time dependent demand. The orders for both products are placed at the same time. Under above assumptions, the objective is to maximize the total profit of the retailer with respect to cycle time and a time at which one product is stock-out.

The remaining part of the paper is organized as follows. Section 2 is the notations and assumptions used for the development of the proposed problem. We derived the model in Section 3. Section 4 represents the solution method to obtain the optimal policy. The numerical study and sensitivity analysis about key parameters is carried out in Section 5. Finally, Section 6 includes the conclusion of the study and its future scopes.

\section{NOTATIONS AND ASSUMPTIONS}

The proposed inventory problem is based on the following notations and assumptions.

\subsection{Notations}

$\begin{array}{ll}a_{i} & \begin{array}{l}\text { Total market potential demand for the } \mathrm{i}^{\text {th }} \\ \text { product, } a>0, \text { where } i=1,2\end{array} \\ b_{i} & \begin{array}{l}\text { Linear rate of change of demand for the } \mathrm{i}^{\text {th }} \\ \text { product, } b \geq 1, \text { where } i=1,2\end{array} \\ c_{i} & \begin{array}{l}\text { Quadratic rate of change of demand for the } \\ \mathrm{i}^{\text {th }} \text { product, } c_{1} \geq 1, \text { where } i=1,2\end{array}\end{array}$




\begin{tabular}{|c|c|}
\hline$e_{i}$ & Rates of inventory level \\
\hline$x$ & $\begin{array}{l}\text { The fraction of demand of the product that } \\
\text { has stocked-out that will be substituted by } \\
\text { the other product during stock-out, } 0<x \leq \\
1\end{array}$ \\
\hline$C_{1 i}$ & $\begin{array}{l}\text { Purchase cost of the } \mathrm{i}^{\text {th }} \text { product per (\$/unit), } \\
\text { where } i=1,2\end{array}$ \\
\hline$p_{i}$ & $\begin{array}{l}\text { Procurement price for the } \mathrm{i}^{\text {th }} \text { product } \\
\text { (\$/unit), } p_{\mathrm{i}} \geq C_{1 i} \text {, where } i=1,2\end{array}$ \\
\hline$\theta_{i}$ & $\begin{array}{l}\text { Constant deterioration rate for the } \mathrm{i}^{\text {th }} \\
\text { product, where } i=1,2\end{array}$ \\
\hline$Q_{i}$ & Initial order quantities for the $\mathrm{i}^{\text {th }}$ product \\
\hline$q$ & $\begin{array}{l}\text { Remaining quantities of product } 2 \text { after } \\
\text { cycle time }\end{array}$ \\
\hline$I_{r i}(t)$ & $\begin{array}{l}\text { The inventory level of the retailer at any } \\
\text { time } t \text { for the } \mathrm{i}^{\text {th }} \text { product }\end{array}$ \\
\hline$h_{i}$ & $\begin{array}{l}\text { Holding cost rate ( } \$ \text { /unit / unit time) for the } \\
\mathrm{i}^{\text {th }} \text { product, where } i=1,2\end{array}$ \\
\hline$A_{r}$ & Fixed ordering cost per lot (\$/lot) \\
\hline$T$ & Cycle time (unit time) (decision variable) \\
\hline$\pi_{r}\left(T, t_{1}\right)$ & The total profit per unit time \\
\hline
\end{tabular}

\section{Relations between parameters:}

- $0 \leq \theta_{1}, \theta_{2}<1$

- $C_{1 i} \leq p_{i}$

The problem is expressed as follows:

$\operatorname{Max}_{r}\left(T, t_{1}\right)$

\subsection{Assumptions:}

1. The inventory system involves substitutable deteriorate items.

2. The demand rate, for each product respectively, is a function of time and instantaneous stock-level $I_{r i}(t)>$ 0 of both products at a certain time. The demand functions of the inventory system are given by $R_{1}\left(t, I_{r 1}(t), I_{r 2}(t)\right)=a_{1}\left(1+b_{1} t-c_{1} t^{2}\right)+e_{1} I_{1}(t)-$ $e_{2} I_{2}(t)$ and $R_{2}\left(t, I_{r 1}(t), I_{r 2}(t)\right)=a_{2}\left(1+b_{2} t-c_{2} t^{2}\right)-$ $e_{1} I_{1}(t)+e_{2} I_{2}(t)$ where, $a_{1}=0$ is total market potential demand, $0 \leq b_{i} \leq 1$ denotes the linear rate of change of demand with respect to time, $0 \leq c_{i}<1$ denotes the quadratic rate of change of demand and $e_{i}>0$ is rates of stock level of each product. $(i=1,2)$

3. The units in inventory system of each player are subject to deterioration at a constant rate. The deteriorated units are not repaired or replaced during the cycle time.

4. At time $t_{1}$ the inventory level of one of the products reaches zero and during $t_{1} \leq t \leq T$, a known fraction $\mathrm{x}$ of the excess demand is met by using the stock of the other product.

5. The ending inventory level of the second product could be greater than or equal to zero.

6. The planning horizon is infinite which will facilitate long time agreement.

7. Lead time is zero or negligible.

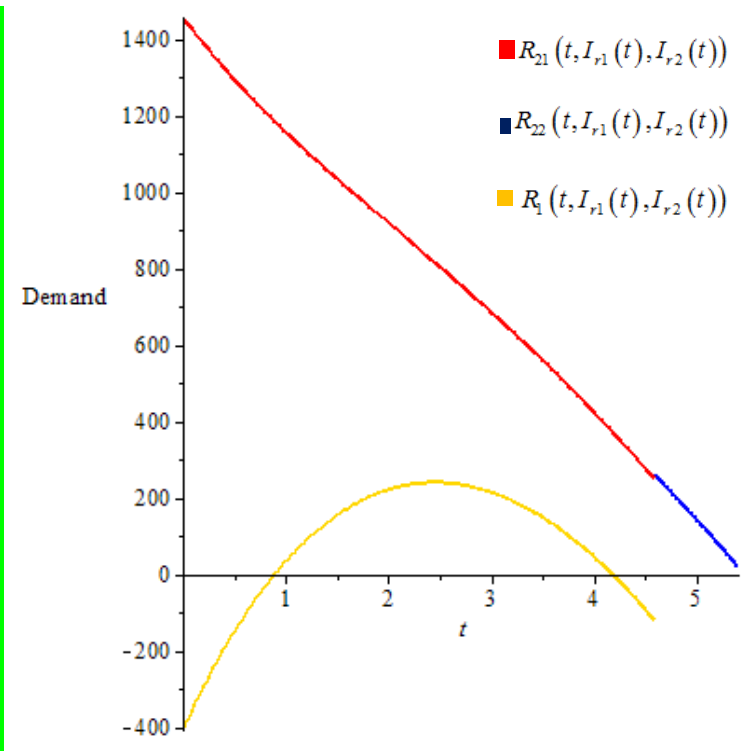

Figure 1 Demand of product 1 and 2 during cycle time

\section{MATHEMATICAL MODEL}

Consider an organization which sells two mutually substitutable products which deteriorate at a constant rate during a cycle time $[0, T]$. One product named as a product 1 and another as a product 2. At the starting of cycle time organization orders $Q_{i}(i=1,2)$ units of each product respectively. Then the stock level of the both product diminish due to demand. We assume that demand of the inventory system is function of time and corresponding stock level of the both the products at a certain time. If at time $t_{1}$ the inventory level of one of the products reaches zero, a known fraction of the demand for that product is fulfilled by using the stock of the other product. The replenishment cycle ends when the inventory level of the second product reaches to zero. In order to conduct the analysis of the problem, without loss of generality, we assume that product 1 is the first to stock-out. The inventory levels for product 1 and 2, respectively, at time $t$ satisfy the following differential equations:

$$
\begin{gathered}
\frac{d I_{r 1}(t)}{d t}=-R_{1}\left(t, I_{r 1}(t), I_{r 2}(t)\right)-\theta_{1} I_{r 1}(t) \\
0<t<t_{1}
\end{gathered}
$$

with the condition $I_{r 1}\left(t_{1}\right)=0$

After depleting the product 1 organization sells product 2 to fulfilled demand of product 1 .

$$
\begin{aligned}
\frac{d I_{r 2}(t)}{d t}= & -R_{2}\left(t, I_{r 1}(t), I_{r 2}(t)\right) \\
& 0<t<t_{1}
\end{aligned}
$$

During the time interval $\left[t_{1}, T\right]$, the inventory level of product 1 is vanished and product 2 can be represented by the following differential equation

$$
\begin{gathered}
\frac{d I_{r 2}(t)}{d t}=-R_{2}\left(t, I_{r 1}(t), I_{r 2}(t)\right)-x \cdot R_{1}\left(t, I_{r 1}(t), I_{r 2}(t)\right) \\
t_{1}<t<T
\end{gathered}
$$

With boundary condition $I_{r 2}(T)=q$ and $I_{r 2}\left(t_{1}^{-}\right)=$

Solving above differential equations, we get inventory level at any time $t$ 


$$
\begin{aligned}
& I_{r 1}(t)=C_{2} e^{\beta_{2} t}-e^{\beta_{2}\left(t-t_{1}\right)}\left(C_{2} e^{\beta_{2} t_{1}}+A_{6} t_{1}^{2}+A_{7} t_{1}+A_{8}\right)+A_{6} t^{2}+A_{7} t+A_{8} \\
& , 0 \leq t \leq t_{1} \\
& I_{r 2}(t)= \\
& \frac{1}{e_{2}}\left(\begin{array}{c}
C_{2} \beta_{2} e^{\beta_{2} t}-\beta_{1} e^{\beta_{1}\left(t-t_{1}\right)}\left(C_{2} e^{\beta_{2} t_{1}}+A_{6} t_{1}^{2}+A_{7} t_{1}+A_{8}\right)+2 A_{6} t+A_{7} \\
+a_{1}\left(-c_{1} t^{2}+b_{1} t+1\right)+\left(e_{1}+\theta_{1}\right) \\
\left(C_{2} e^{\beta_{2} t}-e^{\beta_{1}\left(t-t_{1}\right)}\left(C_{2} e^{\beta_{2} t_{1}}+A_{6} t_{1}^{2}+A_{7} t_{1}+A_{8}\right)+A_{6} t^{2}+A_{7} t+A_{8}\right)
\end{array}\right) \\
& I_{r 2}(t)=\left(\frac{A_{10}+A_{11} t+A_{12} t^{2}}{A_{9}}\right)-\left(\frac{A_{11}+2 A_{12} t}{A_{9}{ }^{2}}\right)+\frac{2 A_{12}}{A_{9}{ }^{3}}+e^{A_{9}(T-t)} \\
& \left(q-\left(\frac{A_{10}+A_{11} T+A_{12} T^{2}}{A_{9}}\right)+\left(\frac{A_{11}+2 A_{12} T}{A_{9}^{2}}\right)-\frac{2 A_{12}}{A_{9}^{3}}\right) \\
& , t_{1} \leq t \leq T
\end{aligned}
$$

where,

$$
\begin{aligned}
& C_{2} \\
& =\frac{1}{A_{9}^{3}\left(\beta_{1}-\beta_{2}\right)}\left(\left(\begin{array}{c}
\left(\begin{array}{c}
-A_{9}^{3} a_{1} c_{1}-A_{12} A_{9}^{2} e_{2} \\
-A_{6} A_{9}^{3} \beta_{1}
\end{array}\right) t_{1}^{2}+\left(\begin{array}{c}
-2 A_{12} e_{2}-A_{8} A_{9}^{3} \beta_{1} \\
+A_{7} A_{9}^{3}+A_{9}^{3} a_{1} \\
-A_{10} A_{9}^{2} e_{2}+A_{11} A_{9} e_{2}
\end{array}\right) \\
+\left(\begin{array}{c}
A_{9}^{3} a_{1} b_{1}-A_{11} A_{9}^{2} e_{2} \\
+2 A_{12} A_{9} e_{2}+2 A_{6} A_{9}^{3}+A_{7} A_{9}^{3} \beta_{1}
\end{array}\right) t_{1} \\
+\left(\begin{array}{c}
-A_{9}^{3} e_{2} q+A_{10} A_{9}^{2} e_{2}-A_{11} A_{9} e_{2} \\
+2 A_{12} e_{2}+A_{12} A_{9}^{2} T^{2} e_{2}+ \\
A_{11} A_{9}^{3} T e_{2}-2 A_{12} A_{9} T e_{2}
\end{array}\right) e^{A_{9}\left(T-t_{1}\right)}
\end{array}\right) e^{-\beta_{2} t}\right)
\end{aligned}
$$

For convenience, the following notations are introduced:

$A_{1}=\left(e_{2}+\theta_{2}\right)\left(e_{1}+\theta_{1}\right)-e_{1} e_{2}, A_{2}=\left(e_{1}+\theta_{1}\right)+\left(e_{2}+\theta_{2}\right)$

$A_{3}=-a_{1} b_{1}-a_{2} e_{2}-\left(e_{2}+\theta_{2}\right) a_{1}, A_{4}=2 a_{1} c_{1}-a_{2} e_{2} b_{2}-\left(e_{2}+\theta_{2}\right) b_{1} a_{1}$

$A_{5}=a_{2} c_{2} e_{2}+a_{1} c_{1}\left(e_{2}+\theta_{2}\right), A_{6}=\frac{A_{5}}{A_{1}}$

$A_{7}=\frac{A_{1} A_{4}-2 A_{5} A_{2}}{A_{1}^{2}}, A_{8}=\frac{A_{1}^{2} A_{3}-2 A_{1} A_{5}-A_{1} A_{4} A_{2}+2 A_{5} A_{2}^{2}}{A_{1}^{3}}$

$A_{9}=e_{2}+\theta_{2}+x e_{2}, A_{10}=-\left(a_{2}+x a_{1}\right)$

$A_{11}=-\left(a_{2} b_{2}+x a_{1} b_{1}\right), A_{12}=a_{2} c_{2}+x a_{1} c_{1}$

$\beta_{1}=\frac{-A_{2}+\sqrt{A_{2}^{2}-4 A_{1}}}{2}, \beta_{2}=\frac{-A_{2}-\sqrt{A_{2}^{2}-4 A_{1}}}{2}$

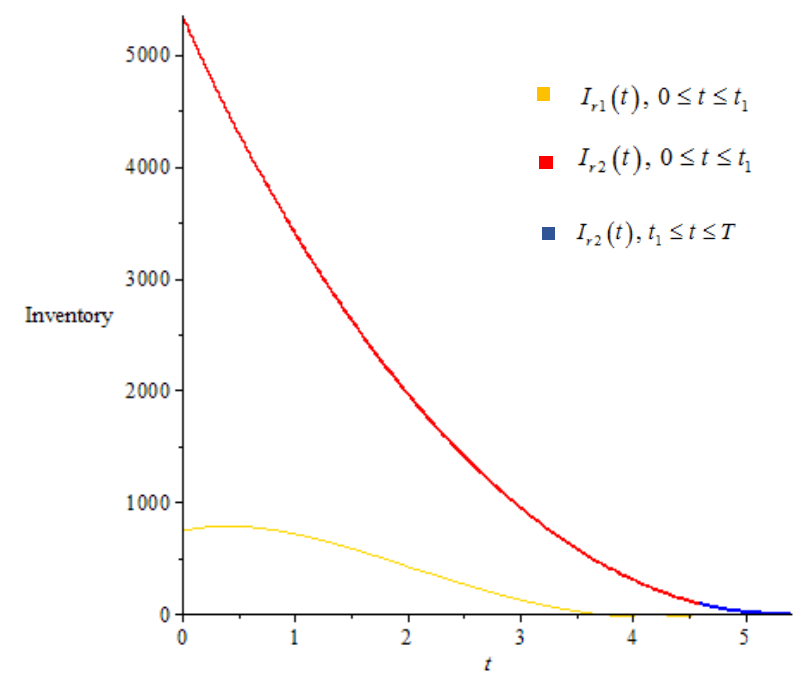

Figure 2 Inventory level of product 1 and 2 during cycle time
In Figure 1 and Figure 2, we have analyzed that after $t_{1}$ when product 1 is stocked out, demand of product 1 fulfilled by product 2 .

Then, the relevant inventory costs can be calculated by considering the following components

$$
\begin{array}{lll}
\text { - Ordering } & : \quad O C_{r}=\frac{A_{r}}{T} \\
\text { of } \\
\text { inventory } \\
\text { cost per } \\
\text { unit time } \\
\text { - Purchase } \\
\text { cost of } \\
\text { item per } \\
\text { unit time }
\end{array}
$$

End of the cycle time retailer can earn sales revenue:

$$
S R_{r}=\frac{1}{T}\left[\int_{0}^{t_{1}}\left(p_{1} Q_{1}+p_{2} Q_{2}\right) d t+\int_{t_{1}}^{T} p_{2} Q_{2} d t\right]
$$

where, $Q_{1}=I_{r 1}(0)$ and $Q_{2}=I_{r 2}(0) q$.

Therefore, the retailer's average profit for item is

$$
\pi_{r}\left(T, t_{1}\right)=S R_{r}-O C_{r}-P C_{r}-H C_{r}
$$

The total profit function $\pi_{r}\left(T, t_{1}\right)$ is a continuous function of cycle time $T$ and a time at which product 1 is stock out. We will established endorsement of the proposed model using numerical example. The maximization of the total profit will be shown graphically for the obtained results.

\section{NUMERICAL EXAMPLE AND SENSITIVITY ANALYSIS}

\subsection{Numerical Example}

Example: Consider the following parameters: scale demand of product 1 is $\mathrm{a}_{1}=500$ units, linear and quadratic rates of demand for the product 1 are $b_{1}=20 \%, c_{1}=10 \%$, rates of inventory level of product 1 is $e_{1}=15 \%$, the fraction of demand of the product that has stocked-out that will be substituted by the other product during stock-out is $\mathrm{x}=10 \%$, holding cost rate of the product 1 is $h=\$ 2 /$ unit/unit time, combine ordering cost for product 1 and 2 is $A=\$ 50 /$ lot, purchase cost of the product 1 is $\mathrm{C}_{11}=\$ 2 /$ unit, constant deterioration rate of the product 1 is $\theta_{1}=25 \%$, and selling price of the product 1 is $p_{1}=\$ 7$, whereas scale demand product 2 is $\mathrm{a}_{2}=500$ units, linear and quadratic rates of demand for the product 2 are $b_{2}=25 \%, c_{2}=10 \%$, rates of inventory level of product 2 is $\mathrm{e}_{2}=20 \%$, holding cost rate of the product 2 is $h=\$ 1.5 /$ unit/unit time, purchase cost of the product 2 is $\mathrm{C}_{12}=\$ 1.5 / \mathrm{unit}$, constant deterioration rate of the product 2 is $\theta_{2}=15 \%$ and selling price of the product 2 is $p_{1}=\$ 8$. Here we consider $q=0$. Using Maple 18 we obtain the optimal values of the decision variables are cycle time $T^{*}$ $=5.304$ unit time and a time at which product 1 is stock out $t_{1}^{*}=4.589$ unit time. So, finally total profit of the inventory system is $\pi_{r}^{*}=\$ 42335.98$. As shown in Figure 3, the unit total profit of the inventory system is concave. 


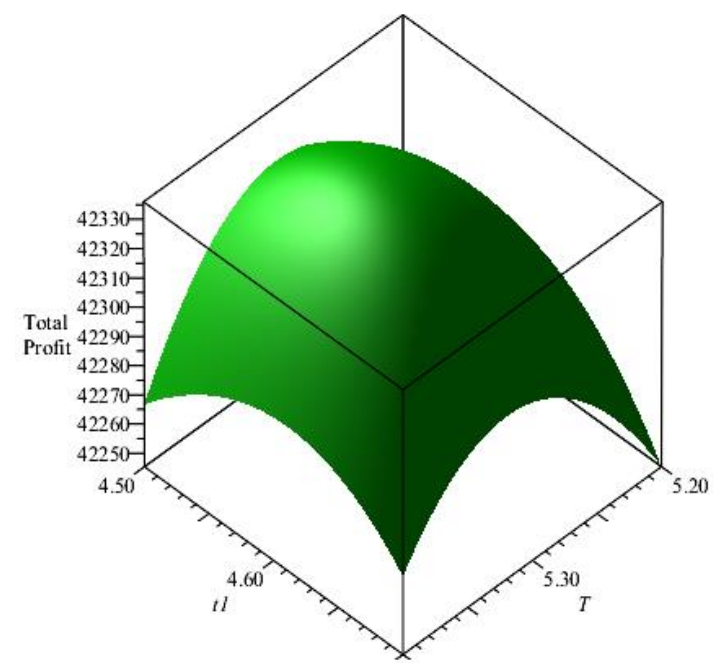

Figure 3 Concavity of the total profit with respect to $T$ and $t_{1}$

Also, the concavity of the profit function is acquired by the well-known Hessian matrix. Now, Hessian matrix is for the above inventory system is

$$
H\left(T, t_{1}\right)=\left(\begin{array}{ll}
\frac{\partial^{2} \pi_{r}\left(T, t_{1}\right)}{\partial T^{2}} & \frac{\partial^{2} \pi_{r}\left(T, t_{1}\right)}{\partial T \partial t_{1}} \\
\frac{\partial^{2} \pi_{r}\left(T, t_{1}\right)}{\partial T \partial t_{1}} & \frac{\partial^{2} \pi_{r}\left(T, t_{1}\right)}{\partial t_{1}^{2}}
\end{array}\right)
$$

Using the above example, we get the hessian matrix $H\left(T, t_{1}\right)$ at the point $\left(T^{*}, t_{1}^{*}\right)$

$$
H\left(T^{*}, t_{1}^{*}\right)=\left(\begin{array}{cc}
-8665.72 & 915.03 \\
915.03 & -5199.87
\end{array}\right)
$$

As in Barrón and Sana (2015), if the Eigen values of the hessian matrix at the solution $\left(T^{*}, t_{1}^{*}\right)$ are all negative, then the profit function $\pi_{r}\left(T^{*}, t_{1}^{*}\right)$ is maximum at that solution. Here, Eigen values of above Hessian matrix are $\lambda_{1}=$ -8892.47 and $\lambda_{2}=-4973.13$. So, the profit function $\pi_{r}\left(T, t_{1}\right)$ is maximum.

\subsection{Sensitivity Analysis}

In Table 2, the sensitivity analysis of some critical inventory parameter of above example is carried out by varying one variable at a time as $-20 \%,-10 \%, 10 \%$, and $20 \%$.

1. From the Table 2, it can be observed that holding cost rate for the $2^{\text {nd }}$ product, purchase cost of both the products and constant deterioration rate for the $2^{\text {nd }}$ product slowly increase the cycle time.

2. From the Table 2, it can be seen that holding cost rate for the $1^{\text {st }}$ product, purchase cost of $1^{\text {st }}$ product and constant deterioration rate for the $2^{\text {nd }}$ product slowly increase whereas holding cost rate for the $2^{\text {nd }}$ product and purchase cost of $2^{\text {nd }}$ product slightly decrease $t_{1}$.

3. From the Table 2 , it can be analyzed that constant deterioration rate for the $1^{\text {st }}$ product rapidly increase whereas holding cost rate and purchase cost for the $2^{\text {nd }}$ product rapidly decrease total profit. Moreover, holding cost rate and purchase cost for the $1^{\text {st }}$ product slowly decrease total profit.

\begin{tabular}{|c|c|c|c|c|c|c|}
\hline \multirow{2}{*}{$\begin{array}{l}\text { Inventory } \\
\text { Parameter }\end{array}$} & \multirow[t]{2}{*}{ Decision variables } & \multicolumn{5}{|c|}{ Change (\%) } \\
\hline & & $-20 \%$ & $-10 \%$ & $0 \%$ & $10 \%$ & $20 \%$ \\
\hline \multirow[t]{2}{*}{$h_{1}$} & $t_{1}$ (unit time) & 4.562 & 4.575 & 4.589 & 4.604 & 4.745 \\
\hline & $\pi$ (in $\$)$ & 42462.32 & 42398.67 & 42335.98 & 42274.33 & 40134.45 \\
\hline \multirow[t]{3}{*}{$h_{2}$} & $T$ (unit time) & 5.293 & 5.299 & 5.304 & 5.310 & 5.315 \\
\hline & $t_{1}$ (unit time) & 4.596 & 4.592 & 4.589 & 4.586 & 4.582 \\
\hline & $\pi($ in $\$)$ & 42853.26 & 42594.45 & 42335.98 & 42077.87 & 41820.12 \\
\hline \multirow[t]{3}{*}{$C_{11}$} & $T$ (unit time) & 5.301 & 5.303 & 5.304 & 5.305 & 5.307 \\
\hline & $t_{1}$ (unit time) & 4.574 & 4.581 & 4.589 & 4.597 & 4.605 \\
\hline & $\pi$ (in $\$$ ) & 42392.96 & 42364.32 & 42335.98 & 42307.95 & 42280.24 \\
\hline \multirow[t]{3}{*}{$C_{12}$} & $T$ (unit time) & 5.298 & 5.301 & 5.304 & 5.307 & 5.310 \\
\hline & $t_{1}$ (unit time) & 4.594 & 4.591 & 4.589 & 4.586 & 4.584 \\
\hline & $\pi($ in $\$)$ & 42638.97 & 42487.41 & 42335.98 & 42184.68 & 42033.52 \\
\hline$\theta_{1}$ & $\pi$ (in \$) & 41241.96 & 41366.11 & 42335.98 & 42627.22 & 42953.53 \\
\hline \multirow[t]{2}{*}{$\theta_{2}$} & $T$ (unit time) & 5.272 & 5.290 & 5.304 & 5.315 & 3.964 \\
\hline & $t_{1}$ (unit time) & 4.585 & 4.587 & 4.589 & 4.591 & 4.760 \\
\hline
\end{tabular}

Table 2 Sensitivity analysis

\section{CONCLUSION}

In this article, we studied inventory control problem of substitutable constant deteriorating items in which demand is fulfilled by using two similar substitutable items. Retailer fulfilled demand of one product by another substitutable product when stock-out of the one of them. We consider inventory levels of both of the items and time dependent demand. The orders for both products are placed at the same time. We analysed with the help of substitutable item one can earn more profit as well as ignore shortages. For numerical examples, inventory control system reaches the maximum profit and carry-out sensitivity analysis with respect to inventory parameters. Current research have numerous 
possible extensions like, model can be further generalized by taken more items at a time and more substitutable items also. One can also analysed multi layered supply chain. Research can be extended for finite or infinite planning horizons.

\section{ACKNOWLEDGMENT}

The first author is thankful to DST- FIST -file \# MSI 097 for the financial assistance to carry out this research.

\section{REFERENCES}

Aggarwal, S.P. and Jaggi, C.K., (1995). Ordering policies of deteriorating items under permissible delay in payments. The Journal of the Operational Research Society, 46 (5), pp. 658-662.

Anupindi R., Dada M. and Gupta S., (1998). Estimation of consumer demand with stock out based substitution: an application to vending machine products. Market Science, 17(4), pp. 406-423.

Avinadav, T., Herbon, A. and Spiegel, U., (2013). Optimal inventory policy for a perishable item with demand function sensitive to price and time. International Journal of Production Economics, 144(2), pp. 497506.

Drezner Z, Gurnani H, Pasternack BA (1995). EOQ model with substitution between products. Journal of the Operational Research Society, 46(7), pp. 887-891.

Dye, C. Y. and Hsieh, T. P., (2012). An optimal replenishment policy for deteriorating items with effective investment in preservation technology. European Journal of Operational Research, 218(1), 106-112.

Dye, C., (2013). The effect of preservation technology investment on a non-instantaneous deteriorating inventory model. Omega, 41(5), pp. 872-880.

Fauza G., Amer Y., Lee S. and Prasetyo H. (2015). A vendorbuyer inventory model for food products based on shelf-life pricing. Operations and Supply Chain Management 8(2), pp. 67-73.

Gerchak Y, Grosfeld-Nir A. (1999). Lot-sizing for substitutable, production-to-order parts with random functionality yields. International Journal of Flexible Manufacturing Systems, 11(4), pp. 371-377.

Ghare, P. M. and Scharender, G. H., (1963). A model for exponentially decaying inventory system. Journal of Industrial Engineering, 14 (5), pp. 238-243.

Goyal, S. K. and Giri, B. C., (2001). Recent trends in modelling of deteriorating inventory. European Journal of Operational Research, 134 (1), pp. 1-16.

Gurnani H., Drezner Z. (2000). Deterministic hierarchical substitution inventory models. Journal of the Operational Research Society, 51(1), pp. 129-133.

Krommyda IP, Skouri K, and Konstantaras I. (2015). Optimal ordering quantities for substitutable products with stock-dependent demand. Applied Mathematical Modeling 39(1), pp. 147-164.

McGillivray AR, Silver EA (1978). Some concepts for inventory control under substitutable demand. Information Systems and Operation Research, 16(1), pp. 47-63.
Mishra BK., Raghunathan S. (2004). Retailer vs. vendormanaged inventory and brand competition. Management Science, 50(4), pp. 445-457.

Pasternack B., Drezner Z. (1991). Optimal inventory policies for substitutable commodities with stochastic demand. Naval Research Logistics, 38, pp. 221-240.

Pattnaik, M. (2012). A note on non-linear profitmaximization entropic order quantity (EnOQ) model for deteriorating items with stock dependent demand rate. Operations and Supply Chain Management 5 (2), pp. 97-102.

Raafat, F. (1991). Survey of literature on continuously deteriorating inventory models. The Journal of the Operational Research Society, 42 (1), pp. 27-37.

Rabbani, M., Zia, N., P. and Rafiei H. (2015). Coordinated replenishment and marketing policies for noninstantaneous stock deterioration problem. Computers \& Industrial Engineering, 88, pp. 49-62.

Rasouli N, Kamalabadi I. (2014). Joint pricing and inventory control for seasonal and substitutable goods mentioning the symmetrical and asymmetrical substitution. Int $J$ Eng (IJE) Trans C Asp, 27(9), pp. 1385-1394.

Salameh M.K., Yassine A.A., Maddah B. and Ghaddar L. (2014). Joint replenishment model with substitution. Applied Mathematical Modelling, 38(14), pp. 36623671.

Schulz A, Telha C. (2011). Approximation algorithms and hardness results for the joint replenishment problem with constant demands. Lecture Notes Computer Science, 6942, pp. 628-639.

Shah, N. H. and Jani, M.Y. (2016). Economic order quantity model for non-instantaneously deteriorating items under order-size-dependent trade credit for pricesensitive quadratic demand. AMSE JOURNALS, 37 (1), pp. 1-19.

Shah, N. H., Gor A. S. and Jhaveri, C. A. (2011). Determination of optimal ordering and transfer policy for deteriorating inventory system when demand is quadratic. International Journal of Management Science and Engineering Management 6 (4), pp. 278283.

Shah, N.H, Soni H. N. and Patel K.A., (2013). Optimizing inventory and marketing policy for non-instantaneous deteriorating items with generalized type deterioration and holding cost rates. Omega 41 (1), pp. 421-430.

Shah, N.H. and Chaudhari U.B. (2015). Optimal Policies for Three Players with Fixed Life Time and Two-Level Trade Credit for Time and Credit Dependent Demand. Advances in Industrial Engineering and Management 4 (1), pp. 89-100.

Shah, N.H., Chaudhari, U. B. and Jani M.Y., (2015). Optimal down-stream credit period and replenishment time for deteriorating inventory in a supply chain. Journal of Basic and Applied Research International, 14 (2), pp. 101-115.

Shah, N.H., Chaudhari, U. B. and Jani M.Y., (2017). Inventory model with expiration date of items and deterioration under two-level trade credit and preservation technology investment for time and price sensitive demand: DCF approach. International Journal of Logistics Systems and Management, 27 (4), pp. 420-437. 
Shah, N.H., Jani M.Y. and Chaudhari, U. B., (2016): Impact of future price increase on ordering policies for deteriorating items under quadratic demand. International Journal of Industrial Engineering Computations, 7, pp. 423-436.

Taleizadeh, A. and M. Nematollahi, (2014). An inventory control problem for deteriorating items with backordering and financial considerations, Applied Mathematical Modelling, 38 (1), pp. 93-109.

Yang, H.L. (2005). A comparison among various partial backlogging inventory lot-size models for deteriorating. International Journal of Production Economics, 96 (1), pp. 119-128.

Zhang, J., Liu, G., Zhang, Q., and Bai, Z. (2015). Coordinating a supply chain for deteriorating items with a revenue sharing and cooperative investment contract. Omega, 56 (1), pp. 37-49.

Zhao J, Wei J, Li Y (2014). Pricing decisions for substitutable products in a two-echelon supply chain with firms different channel powers. International Journal of Production Economics, 153, pp. 243-252.

Nita H. Shah is a Professor in the Department of Mathematics, Gujarat University, Ahmedabad. She has 20 years of research experience in inventory management, forecasting and information technology and information systems. She has published 450+ articles in international journals, including APJOR (Singapore), International Journal of Production Economics, OMEGA, CCERO (Belgium), ECPE (Romania), Measuring, Control \& Simulation (France), JIOS (India), IJOMS (India), Industrial Engineering (India), European Journal of Operational Research, IJOR, IJMOR, IJBPSCM, etc.

Urmila Chaudhari is a Lecturer in the Government Polytechnic Dahod, Gujarat, India. Her research interests are in the fields of Supply chain inventory modelling for different payment options. She has published 19 articles in international journals, including Revista Investigacion Operacional, IJIR, JOBARI and IJIEC, Taylor and Francis, Springer, IGI Global, Growing Sciences, IJOQM, AMSE and IJMOR.

Mrudul Y. Jani is an Assistant Professor in the Department of Applied Sciences, Faculty of Engineering and Technology at Parul University, Vadodara, Gujarat, India. His research interests are in the fields of inventory management under deterioration and different demand structures. He has published 19 articles in international journals, including Revista Investigacion Operacional, JOBARI and IJIEC, Taylor and Francis, Springer, IGI Global, Growing Sciences, IJOQM, AMSE and IJMOR. 